\title{
THE EFFECTS OF READING TOPIC AND TOPIC PREFERENCE ON READING COMPREHENSION
}

\author{
Hesty Widiastuty \\ Universitas Muhammadiyah Palangka Raya \\ hestywidiastuty87@gmail.com
}

\begin{abstract}
This study is aimed at investigating the interaction effect of reading topic and topic preference, the effect of reading topic, and the effect of topic preference on Physics score, Biology score, and Chemistry score of single cause-multiple effects text. The population of this study was the eleventh grade of IPA students of SMA Negeri 2 Kuala Kapuas in Academic Year 2008/2009. There were 64 students of two classes (XI IA ${ }^{1}$ and IX IA ${ }^{2}$ ) as the sample of this study chosen by using cluster random sampling. It was used experimental research with factorial experimental design. The data were processed and analyzed through these steps: taking the data, coding scoring, tabulating, analyzing the data by using statistic technique of ANOVA processed by using SPSS 15 and taking the conclusion based on the statistical result. The results show that: (1) there was significant interaction effect among reading topic and topic preference on Physics score, Biology score, and Chemistry score of single cause-multiple effects text, (2) there was no significance effect of reading topic of single cause-multiple effects text, and (3) there was no significance effect of topic preference on Physics score, Biology score, and Chemistry score of single cause-multiple effects text.
\end{abstract}

Keywords: reading topic, topic preference, reading comprehension

Reading is a major way to learn English. Reading ability is a basic and significant criterion to scale one's English level. Schema plays an important role in the process of reading. Eskey et al. in Toendan (1996:33) defined viewed the framework of schema theory, reading is an interactive process between the reader's background knowledge and the text. Specifically, reading is an interaction between information obtained by bottom-up decoding and information provided by means of top-down analysis, both of which depend on certain kinds of prior knowledge and certain kinds of information-processing skills.

Rumelhart \& Ortony in Toendan (1996:33) defined schemata are the key units of comprehension process, in the sense that comprehension consists of selecting schemata and variable bindings that will account for the material to be comprehended, and then varying that those schemata do indeed account for it. Simanjuntak (1988:16) stated that a background that provides a basic understanding of the vocabulary and enables the student to apply concrete illustrations of the new ideas forms the base on which he could build the new information. 
In addition, Toendan (1996:34) said that the principle results two basic modes of information processing, called bottomup and top-down processing. Schemata are hierarchically organized, from most general at the top to most specific at the bottom. As these bottom-level schemata converge into higher-level schemata (more general schemata), these schemata become activated. This process is also referred to as data-driven processing, because it is evoked by the incoming data. Top-down processing occurs when reader use his higher-level schemata to make general predictions about the data he will find in a text. This information processing is also referred to as conceptually driven processing.

According to Carrell in Toendan (1996:33), there are three major types of schemata, which are closely interrelated to reading comprehension: Linguistics Schemata, refers to the readers' knowledge of the language used (vocabulary, grammar and idioms) in the text. They are the foundation of other schemata. Linguistic knowledge plays an essential part in text comprehension. Without linguistic schemata, it is impossible to the reader to decode and comprehend a text. Therefore, the more linguistic schemata a reader has in his mind, the faster the reader acquires information and the better understanding the reader may get. Formal Schemata, refers to knowledge of the rhetorical organization of the text. They include knowledge of different text types and genres, and also include the knowledge that different types of texts use text organization, language structures, vocabulary, grammar and level of formality differently. Formal schemata are described as abstract, encoded, internalized, coherent patterns of metalinguistic, discourse and textual organization that guide expectation in our attempts to understand a meaning piece of language. Readers use their schematic representations of the text such as fictions, poems, essays, newspaper articles, academic articles in magazines and journals to help comprehend the information in the text.

The next one is Content Schemata. It refers to the background knowledge of the content area of a text, or the topic a text talks about. They include topic familiarity, cultural knowledge and previous experience with a field. Content schemata deal with the knowledge relative to the content domain of the text, which is the key to the understanding of texts (Carrell in Toendan, 1996:33). Since one language is not only the simple combination of vocabulary, sentence structure and grammar but also the bearer of different levels of the language's culture. To some extent, content schemata can make up for the lack of language schemata, and thus help learners understand texts by predicting, choosing information and removing ambiguities. On the whole, the familiarity of the topic has a direct influence on readers' comprehension. The more the reader knows about the topic, the more easily and quickly he gets the information of the text. Therefore, if one wants to be an efficient reader, he needs to try to know the knowledge about more fields and topics. Learners with more prior knowledge can better comprehend and remember more the text.

From the explanation above, it can be said that the knowledge of reading should be sufficient to increase students' comprehension. Background knowledge 
of students is different especially in class program. The background knowledge of the students majoring in natural science (IPA students) was different from the students majoring in social science (IPS students). In schema theory, it is different in language used in the text, content area of the text, and knowledge of rhetorical structure of the texts. It means that the readers difficulty in comprehending and construct the meaning of the text if they have different background knowledge. Shnayer in Purves \& Beach (1969:97) showed that high interests resulted in significantly greater comprehension and enabled students to read beyond their reading ability level. This statement is supported by Coady in Carrell et al. (1988:75), “The interest and background knowledge will enable to student to comprehend at a reasonable and keep him involved in the material in spite of its syntactic difficulty".

In relation to natural science (IPA) it is defined as a way or method to observe something through logical and uniform of thought. IPA views something correctly, and accurately that related to one object to the other object to form new perspective about the object is observed. Students who are classified into IPA study program focused on studying math and natural science, such physics, chemistry, and biology than the other subject. According to Terman \& Lima in Purves \& Beach (1969:70), it is stated that "Reading interest is a stronger interest in more realistic subject matter develops as students begin to read more on their own and begin to perceive reading as a source of information".

Based on the background of the study, the problems of the study were as follows, "(1) What is the interaction effect of reading topic and topic preference on Physics score, Biology score, and Chemistry score of single cause-multiple effects text? (2) What is the effect of reading topic on Physics score, Biology score, and Chemistry score of single cause-multiple effects text? And (3) What is the effect of topic preference on Physics score, Biology score, and Chemistry score of single cause-multiple effects text of the Eleventh Grade of IPA students of SMA Negeri 2 Kuala Kapuas?"

The study was expected to give meaningful contributions. The results of the study can be the source of the teaching material for the teacher especially on reading subject, and It can be the source of the teacher to know more about effect of reading topic and topic preference on reading comprehension of single causemultiple effects text. Also, the result of this study can be as a contribution to the students to improve their skill in reading especially in learning single causemultiple effects text.

\section{METHOD}

The study applied experimental research with factorial experimental design. The data were processed and analyzed through these steps: taking the data, coding scoring, tabulating, analyzing the data by using statistic technique of ANOVA processed by using SPSS 15 and taking the conclusion based on the statistical result.

The data needed in this study were taken from the students' scores on the reading comprehension test. The data were collected from the reading comprehension test, in order to represent the interaction effect of reading topic and 
topic preference, the effect of reading topic, and the effect of topic preference on Physics score, Biology score, and Chemistry score of single cause-multiple effects text of the Eleventh Grade of IPA students of SMA Negeri 2 Kuala Kapuas in Academic Year 2009/2010.

The criteria for the admissibility of the data were as follows: (1) The data were taken from the result of comprehending topic preference of single cause-multiple effects text of the reading test that was scores. (2) The data were focused to find out the interaction effect of reading topic and topic preference, the effect of reading topic, and the effect of topic preference in comprehending single cause-multiple effects text. (3) The data were collected from the Eleventh Grade of IPA students of SMA Negeri 2 Kuala Kapuas by using reading comprehension test.

The instruments used reading comprehension tests in form of Multiple Choice Questions (MCQ). Multiple Choice Questions (MCQ) was one of test that allows the student to choose the correct option from the option that has been given. Multiple Choice Questions (MCQ) consisted of the questions, which related about Single Cause-Multiple Effects text.

Besides, it was also used questionnaires as the second instrument that is used for the additional data of the study and also to found out the unforeseen problems that cannot be detected by multiple-choice questions. The purpose of using questionnaire was to know student's preference on Reading Comprehension related to their teaching learning process. The forms of questionnaire that the writer used were open-ended format and likert.
In this study, the text was used approximately 150-350 words. To know the difficulty level of the text is comparable, the writer used flesch reading ease and flesch Kincaid of readability by Microsoft Word 2007 in this study. The flesch reading ease, a score is approximately 50-70, and the Flesch Kincaid grade level is approximately 9-10. The instrument was used as a tool of collecting the data needed.

\section{FINDINGS}

Based on the analysis, the findings shows that the student achievement in the effect of reading topic and topic prereferences on reading comprehension was not satisfactory yet. A great number of researches on schema theory have been conducted and the achievements have shown that the theory is useful in helping improve students' reading ability. There are many skills of English which should be mastered and it is cannot be denied that reading is one of the most important skills in English. As we know that Reading Comprehension is the way or process in cognitive side for putting the message and finding the information from the written materials. The existing reading modals, however, can be classified into three categories according to the three general principles of how reading is assumed to be processed. They are bottom-up, top-down, and interactive processing. 


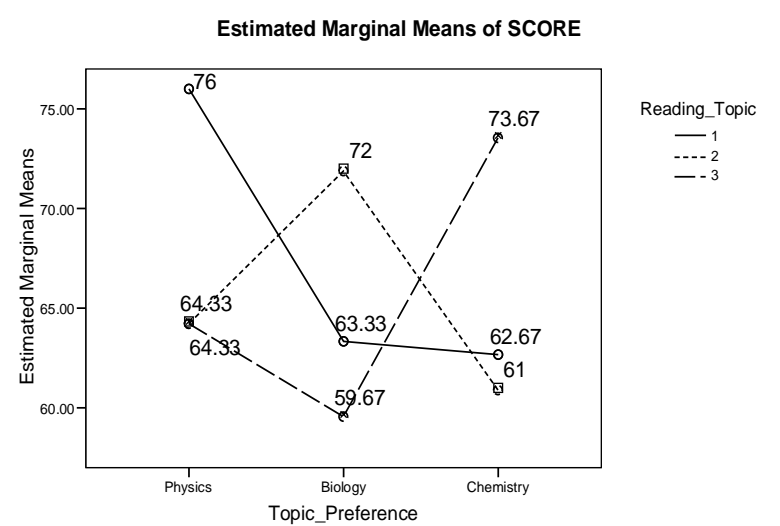

It is known that comprehension of the text is influenced by some factors, such as kind of topic of text, reader's oral language, attitude, purpose of reading, and so on. Those factors play important role to influence the reader's comprehension. Vallete (2002:246) stated that reading is a development process. Therefore, it can be concluded that reading is a mental process, which can develop our knowledge and skill. Reading is a "meaning-constructing system" that readers use to try to understand a text by relating it to what they already know.

Moreover, a good understanding of a piece of writing is facilitated by the reader's recognition of the topic and of the main idea contained.Reading comprehension here referred to student's score of IPA class program after receiving treatment 1 in form of Physics Topic, treatment 2 in form of Biology Topic, and treatment 3 in form of Chemistry Topic. The results were physics score, biology score, and chemistry score. The reader's interest in the topic influences his or her reading ability rate. Interest as a factor in comprehension is significantly more important for low comprehension groups than high comprehension groups. For readers at or below reading levels, low interest has a negative effect on comprehension. The results of this study give credence to attempts to enhance reading interests as a means of improving reading skills. The more interesting a reader in a text is, the easier it is to understand. One of factors that influenced reader to comprehend the meaning of text is the content area.

Based on the result of analysis on the data gained from the Eleventh Grade of IPA students by conducted reading comprehension test. In this study, the writer used the instrument to collect the data needed and measure the ability of students on reading comprehension of single cause-multiple effects text. the purpose of the instrument was to investigate the interaction effect of reading topic and topic preference, the effect of reading topic, and the effect of topic preference on Physics score, Biology score, and Chemistry score of single cause-multiple effects text attained by the Eleventh Grade of IPA students of SMA Negeri 2 Kuala Kapuas.

In analyzing the data, the writer interpreted the data from the table of ANOVA. The result of the test of WithinSubjects Effects can be seen on Table 1. 
Table 1. Summary of Topic Preference Normality Decisions

\begin{tabular}{|c|c|c|c|c|c|c|}
\hline \multirow{2}{*}{\multicolumn{2}{|c|}{ Topic Preference }} & \multicolumn{3}{|c|}{ Kolmogorov-Smirnov } & \multirow{2}{*}{$\begin{array}{l}\text { Difference } \\
\text { compared to } \\
\text { Normal } \\
\text { Distribution }\end{array}$} & \multirow[b]{2}{*}{ Decision } \\
\hline & & Stat. & df & Sig. & & \\
\hline \multirow{3}{*}{$\begin{array}{l}\text { Physics } \\
\text { Score }\end{array}$} & Physics & .175 & 15 & $.200^{*}$ & $\begin{array}{l}\text { Not close to } \\
\text { significant }\end{array}$ & Normally distributed \\
\hline & Biology & .200 & 15 & .107 & $\begin{array}{l}\text { Not close to } \\
\text { significant }\end{array}$ & Normally distributed \\
\hline & Chemistry & .182 & 15 & .195 & $\begin{array}{l}\text { Not close to } \\
\text { significant }\end{array}$ & Normally distributed \\
\hline \multirow{3}{*}{$\begin{array}{l}\text { Biology } \\
\text { Score }\end{array}$} & Physics & .214 & 15 & .063 & Nearly significant & Normally distributed \\
\hline & Biology & .181 & 15 & $.200^{*}$ & $\begin{array}{l}\text { Not close to } \\
\text { significant }\end{array}$ & Normally distributed \\
\hline & Chemistry & .213 & 15 & .066 & Nearly significant & Normally distributed \\
\hline \multirow{3}{*}{$\begin{array}{l}\text { Chemistry } \\
\text { Score }\end{array}$} & Physics & .214 & 15 & .063 & Nearly significant & Normally distributed \\
\hline & Biology & .216 & 15 & .058 & Nearly significant & Normally distributed \\
\hline & Chemistry & .166 & 15 & $.200^{*}$ & $\begin{array}{l}\text { Not close to } \\
\text { significant }\end{array}$ & Normally distributed \\
\hline
\end{tabular}

In analyzing the data, the writer interpreted the data from the table of
ANOVA. The result of the test of WithinSubjects Effects can be seen on Table 2.

\section{Table 2. Tests of Within-Subjects Effects}

Tests of Within-Subjects Effects

\begin{tabular}{|c|c|c|c|c|c|c|}
\hline Source & & $\begin{array}{l}\text { Type III Sum } \\
\text { of Squares }\end{array}$ & $\mathrm{df}$ & Mean Square & $\mathrm{F}$ & Sig. \\
\hline \multirow[t]{4}{*}{ Reading_Topic } & Sphericity Assumed & 67.778 & 2 & 33.889 & 1.368 & .260 \\
\hline & Greenhouse-Geisser & 67.778 & 1.942 & 34.909 & 1.368 & .260 \\
\hline & Huynh-Feldt & 67.778 & 2.000 & 33.889 & 1.368 & .260 \\
\hline & Lower-bound & 67.778 & 1.000 & 67.778 & 1.368 & .249 \\
\hline \multirow{4}{*}{$\begin{array}{l}\text { Reading_Topic * } \\
\text { Topic_Preference }\end{array}$} & Sphericity Assumed & 3917.778 & 4 & 979.444 & 39.533 & .000 \\
\hline & Greenhouse-Geisser & 3917.778 & 3.883 & 1008.942 & 39.533 & .000 \\
\hline & Huynh-Feldt & 3917.778 & 4.000 & 979.444 & 39.533 & .000 \\
\hline & Lower-bound & 3917.778 & 2.000 & 1958.889 & 39.533 & .000 \\
\hline \multirow[t]{4}{*}{ Error(Reading_Topic) } & Sphericity Assumed & 2081.111 & 84 & 24.775 & & \\
\hline & Greenhouse-Geisser & 2081.111 & 81.544 & 25.521 & & \\
\hline & Huynh-Feldt & 2081.111 & 84.000 & 24.775 & & \\
\hline & Lower-bound & 2081.111 & 42.000 & 49.550 & & \\
\hline
\end{tabular}

Based on Table 2, the result of within-subjects effects can be interpreted as follows. For interaction of reading topic and topic preference, the $\mathrm{P}$ value of Greenhouse-Geisser was .000. It considered extremely significant, since .000 was less than .001. meanwhile, for reading topic, the $\mathrm{P}$ value of GreenhouseGeisser was .260. It considered not close to significant, because .260 was more than .10 and less than .50 .

The interpretation about withinsubjects effects above shows only $\mathrm{P}$ value for interaction of reading topic and topic 
preference considered extremely significant. It meant that interaction among reading topic and topic preference significantly affected the dependent variable (physics score, biology score, and chemistry score).

The question that remains is that how interaction among reading topic and topic preference affected the dependent variable with three levels. Therefore, the main effect of reading topic and topic preference needs to be discussed later on hypothesis testing. Then, here the interpretation for between-subjects effects in this study.

\section{Table 3. Tests of Between-Subjects Effects}

\section{Tests of Between-Subjects Effects}

Measure: SCORE

Transformed Variable: Average

\begin{tabular}{|l|r|r|r|r|r|}
\hline Source & $\begin{array}{c}\text { Type III Sum } \\
\text { of Squares }\end{array}$ & df & Mean Square & F & Sig. \\
\hline Intercept & 594015.000 & 1 & 594015.000 & 5000.839 & .000 \\
\hline Topic_Preference & 254.444 & 2 & 127.222 & 1.071 & .352 \\
\hline Error & 4988.889 & 42 & 118.783 & & \\
\hline
\end{tabular}

Based on Table 3, the effects of between-subjects can be interpreted as follows. The $\mathrm{P}$ value of topic preference was .352. It considered not close to significant, because .352 was more than .10 and less than .50. The explanation above showed that between-subjects effect (topic preference) is considered not close to significance. It meant the between subjects (topic preference) did not affect the dependent variable (physics score, biology score, and chemistry score) significantly. Therefore, the discussion on between-subjects effects can be neglected.

Next, this study also questioned about the mean differences of each level of the main effect (reading topic and topic preference). From the interpretation on within-subjects section, interaction of reading topic and topic preference had significant effect on the dependent variable (physics score, biology score, and chemistry score).
Thus, the writer also focused the discussion to find out the mean differences of interaction of reading topic and topic preference. Discussion about the mean difference for reading topic and topic preference can be neglected because they had no significant effect. The interpretation was known from table called Estimates, and it supported graphically by profile plot.

\section{Hypothesis Testing}

There were three hypotheses in this study in which each consisted of two kinds of hypotheses, they were null hypotheses $\left(\mathrm{H}_{0}\right)$ and alternative hypotheses $\left(\mathrm{H}_{\mathrm{a}}\right)$ that need to be proved. The result of the hypotheses could be seen as follow:

Hypothesis Testing of Interaction Effect of Reading Topic and Topic Preference

Based on the analysis WithinSubjects Effects, the $P$ value of interaction effect of reading topic and topic 
preference was .000 . It could be considered extremely significant. In the other word, $\mathrm{Ho}_{1}$ was rejected and $\mathrm{H}_{\mathrm{a}}$ was accepted. Therefore, there was significant interaction effect of reading topic and topic preference on Physics Score, Biology Score, and Chemistry Score of Single Cause-Multiple Effects text attained by the Eleventh Grade IPA students of SMA Negeri 2 Kuala Kapuas

\section{Hypothesis Testing of Reading Topic}

Based on the analysis WithinSubjects Effects, the $\mathrm{P}$ value of reading topic was .260 . It could be considered not close to significant. In the other word, $\mathrm{Ho}_{2}$ was accepted and $\mathrm{H}_{a}$ was rejected. Therefore, there was no significance effect of reading topic on Physics Score, Biology Score, and Chemistry Score of Single Cause-Multiple Effects text attained by the

Table 4. Summary of Hypothesis Testing

\begin{tabular}{llllcl}
\hline No. & \multicolumn{1}{c}{ Hypothesis } & $\begin{array}{c}\text { Kind of } \\
\text { Effect }\end{array}$ & $\begin{array}{c}\text { Kind of } \\
\text { Subject }\end{array}$ & $\begin{array}{c}\text { Ho/H } \\
\text { accepted }\end{array}$ & Interpretation \\
\hline 1. & $\begin{array}{l}\text { Reading Topic }{ }^{*} \text { Topic } \\
\text { Preference }\end{array}$ & Interaction & Within & $\mathrm{H}_{1}$ & There was... \\
\hline 2. & Reading Topic & Main Effect & Within & $\mathrm{H}_{0}$ & There was no... \\
\hline 3. & Topic Preference & Main Effect & Between & $\mathrm{Ho}_{0}$ & There was no... \\
\hline
\end{tabular}

\section{DISCUSSION}

Based on the testing of hypothesis, $\mathrm{H}_{01}$ was rejected and $\mathrm{H}_{\mathrm{a}}$ was accepted since based on the statistical data that had been presented, the result of the study showed that there was interaction significance effects of reading topic and topic preference on Physics score, Biology score, and Chemistry score of single cause-multiple effects text of the Eleventh Grade IPA students of SMA Negeri 2 Kuala Kapuas.

Although at first, the writer assumed that interaction of reading topic and topic preference was no significant effect on
Eleventh Grade IPA students of SMA Negeri 2 Kuala Kapuas. The next table showed estimated marginal means of topic preference.

\section{Hypothesis Testing of Topic Preference}

Based on the analysis WithinSubjects Effects, the $\mathrm{P}$ value of reading topic was .352. It could be considered not close to significant. In the other word, $\mathrm{Ho}_{3}$ was accepted and $\mathrm{H}_{\mathrm{a}}$ was rejected.

Therefore, there was no significance effect of topic preference on Physics score, Biology score, and Chemistry score of single cause-multiple effects text attained by the Eleventh Grade IPA students of SMA Negeri 2 Kuala Kapuas. The next table shows estimated marginal means of topic preference. The hypothesis testing above could be summarized into Table 4 .

physics score, biology score, and chemistry score of single cause-multiple effects text, but it was not proved by the result of the study. Statistically, the $p$ value of the interaction significance effect of reading topic and topic preference on reading comprehension of single causemultiple effects text was considered extremely significant. It meant that the interaction effect of reading topic and topic preference on physics score, Biology score, and Chemistry score of single cause-multiple effects text was so strong. Therefore, it meant the interaction effect of reading topic and topic preference had 
great significant effect on Physics score, Biology score, and Chemistry score of single cause-multiple effects text.

Some factor influences the significant of the hypothesis. Based on the result of questionnaire as the additional information, it showed that mostly students said the most frequent skill taught by teacher $86.66 \%$ is speaking so they are not focus on structure. In teaching reading based on the result of questionnaire said, teacher commonly assigns students to answer question about the text with $55.55 \%$ so the students familiar with reading test without care about the structure on the text. Based on the result of the questionnaire for students, this effect occurred because of some factors, such as:

1. Students claimed that they had learnt about reading topic $84.44 \%$, and had learnt about topic preference $77.77 \%$. Most of the students said $(73.33 \%)$ that they had good comprehension about reading topic. Most of the students said $(71.11 \%)$ that they had good comprehension about topic preference. Whether most of them said that they had learnt about reading topic and topic preference, but it could be seen from the percentage of the students answer that students have problem in identifying main idea $62.22 \%$. It also could be seen that student's felling toward identification of Main Idea and Details $71.11 \%$ said easy and $28.89 \%$ said difficult. It concluded that interaction of reading topic and topic preference has great effect on reading comprehension because they had ever learnt about thesis statement and main idea and they feel easy identifying that.

2. Based on the result of questionnaire, in teaching reading, teacher commonly assigns the students to answer question about the text with 55.55\%, and students said that $64.44 \%$ clear about teacher's performance in explaining the topic of English. Based on some facts above there are the reasons why there was interaction significant effect of reading topic and topic preference.

Based on the testing of hypothesis, $\mathrm{H}_{01}$ was accepted and $\mathrm{H}_{a}$ was rejected since based on the statistical data, the result of the study showed that there was no significant effect of reading topic on Physics score, Biology score, and Chemistry score of single cause-multiple effects text of the Eleventh Grade IPA students of SMA Negeri 2 Kuala Kapuas. Statistically, the $p$ value of the effects of reading topic on Physics score, Biology score, and Chemistry score of single cause-multiple effects text was considered not close to significant. It means that effect of reading topic on Physics score, Biology score, and Chemistry score of single cause-multiple effects text was not so strong. Therefore, it means that the effect of reading topic had no great significant effect on physics score, biology score, and chemistry score of single cause-multiple effects text.

Based on the testing hypothesis 3, $\mathrm{H}_{03}$ was accepted and $\mathrm{H}_{1}$ was rejected, where there was no significant effect of topic preference on Physics score, Biology score, and Chemistry score of single cause-multiple effects text. Statistically, the $\mathrm{p}$ value of the effects of reading topic on Physics score, Biology score, and 
Chemistry score of single cause-multiple effects text was considered not close to significant. It means that effect of topic preference on Physics score, Biology score, and Chemistry score of single causemultiple effects text was not so strong. Therefore, it means that the effect of topic preference had no great significant effect on Physics score, Biology score, and Chemistry score of single cause-multiple effects text.

Because the writer delimited her study on single cause-multiple effects text and IPA Program used, therefore, the result of this study could not be generalized to the other text pattern, and because the sample was taken using cluster random sampling technique and simple random sampling technique, thus the result of this study could be generalized only to the Eleventh Grade IPA students as SMA Negeri 2 Kuala Kapuas.

\section{CONCLUSION}

In this study, it was concluded that, first, there was interaction significant effect of reading topic and topic preference on Physics score, Biology score, and Chemistry score of single causemultiple effects text of the Eleventh Grade IPA students of SMA Negeri 2 Kuala Kapuas. Second, there was no significant effect of reading topic on Physics score, Biology score, and Chemistry score of single cause-multiple effects text of the Eleventh Grade IPA students of SMA Negeri 2 Kuala Kapuas. Third, there was no significant effect of topic preference on Physics score, Biology score, and Chemistry score of single cause-multiple effects text of the Eleventh Grade IPA students of SMA Negeri 2 Kuala Kapuas.
Following the conclusion, there were recommendations. It is important to teach thesis statement, main idea, and supporting details because this basic knowledge will help the students to have good comprehension in reading English sources (printed). Then it is recommended to the teacher need to using the material that suitable and up-to-date for the students based on their interested in order to make them easier in comprehending the material. Next, it is suggested to the students to improve their interest in reading. Because by reading they can get much information and can improve their performance in English subject. Finally, it is suggested to the next researchers who are interested in conducting the similar topic to add a new variable in order to validate this study, such as a gender oriented topic and use an enormous population.

\section{REFERENCES}

Carrel, P. L., Devine, J. \& Eskey, D. E. (1988). Interactive approaches to second language reading. New York: Cambridge University Press.

Purves, A. C. \& Beach, R. (1969). Literature and the reader. Urbana-Champaign: University of Illinois.

Simanjuntak, E. G. (1988). Developing reading skill for EFL students. Jakarta: Depdiknas.

Toendan, W. (1996). Effects of the schematic factors on the EFL reading comprehension. Unpublised Dissertation. Malang: IKIP Malang. Vallete. (2002). Membaca adalah sebuah proses yang berkembang (a developmental process). Jurnal Pendidikan dan Kebudayaan, 37. 